\title{
Correction to: Species richness patterns, hotspots and phytogeographic affinities of thalloid liverworts (Marchantiophyta) and hornworts (Anthocerotophyta) of Sri Lanka
}

\author{
N. C. Sumudu Ruklani ${ }^{1,2}$ - Sumudu C. K. Rubasinghe $e^{1,2}$
}

Published online: 26 February 2021

(c) International Society for Tropical Ecology 2021

\section{Correction to: Tropical Ecology \\ https://doi.org/10.1007/s42965-020-00132-3}

The original article unfortunately contained a mistake: Figure 9 was not displayed correctly. The correct Fig. 9 is shown below.

The original article has been corrected.

Fig. 9 Location of Indian Plate in the equatorial belt at around 45 MYA

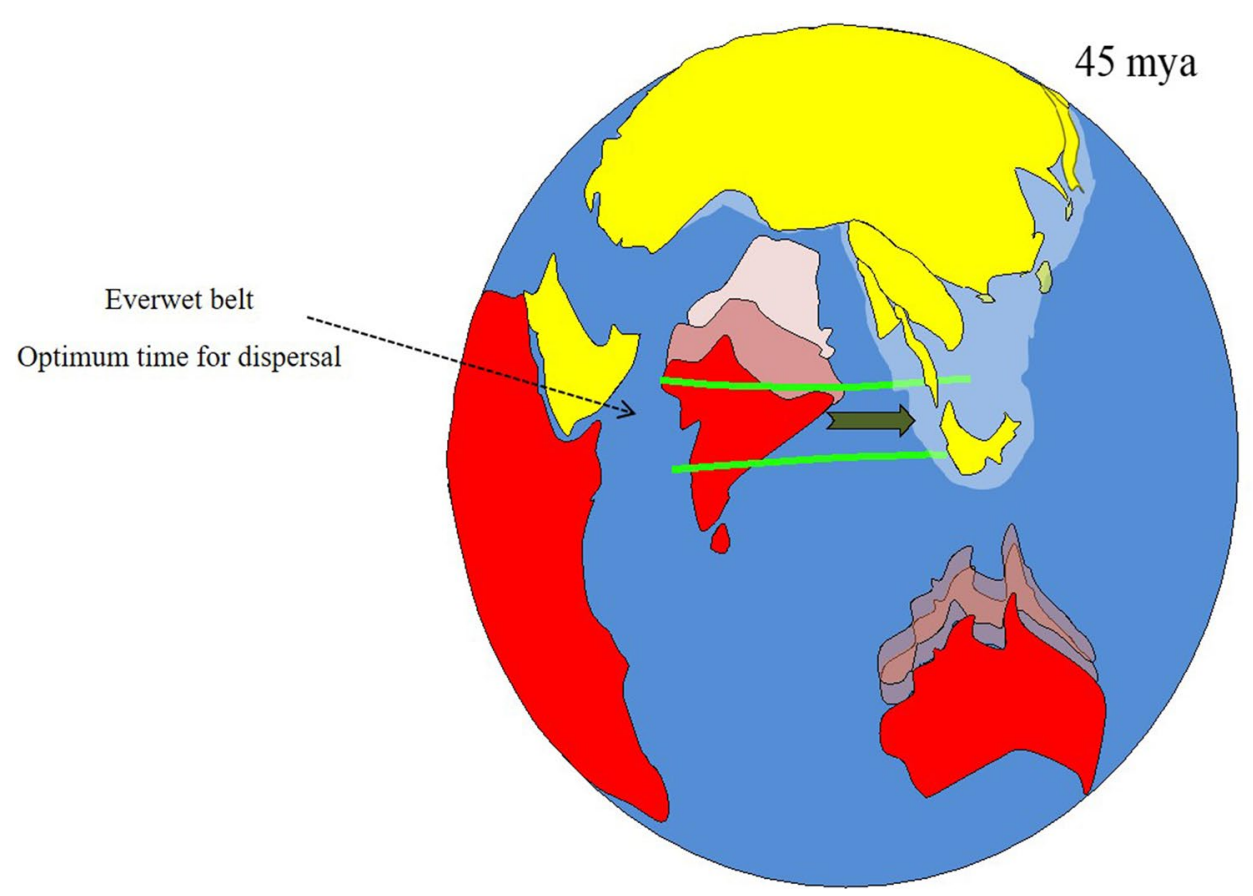

The original article can be found online at https://doi.org/10.1007/ s42965-020-00132-3.

N. C. Sumudu Ruklani sumuwish89@gmail.com

1 Department of Botany, Faculty of Science, University of Peradeniya, Peradeniya 20400, Sri Lanka

2 Postgraduate Institute of Science, University of Peradeniya, Peradeniya 20400, Sri Lanka 